\title{
Aydınlık Karanlık Kutusu Testi’nin Biyolojik ve Biyolojik Olmayan Faktörler Açısından İncelenmesi
}

\author{
Hasan Çalışkan ${ }^{1}$,Koray Hamza Cihan ${ }^{2}$, Zakir Osmanov ${ }^{2}$, Süleyman Kılınç ${ }^{2}$, Mitat Can Öztürk ${ }^{2}$, Murat \\ Kılıçdağ $1^{2}$, Mehmet Oğuzhan Kaya ${ }^{2}$, Şükrü Hakan Gencer ${ }^{2}$, Ahmet Ergün ${ }^{1}$, Nezahat Zaloğlu ${ }^{1}$ \\ ${ }^{1}$ Ankara Üniversitesi Tıp Fakültesi, Fizyoloji Anabilim Dalı, Ankara \\ ${ }^{2}$ Ankara Üniversitesi Tip Fakültesi, Ankara \\ E mail: hasanmonica@hotmail.com
}

\begin{abstract}
Özet
Aydınlık karanlık kutusu testi davranış fizyolojisinde kullanılan şartsız bir anksiyete testidir. Bu derlemede aydınlık karanlık kutusu testinde bazı noktaları standardize etmek amacıyla biyolojik ve biyolojik olmayan faktörler açısından incelenmiştir.
\end{abstract}

Anahtar Kelimeler: anksiyete testleri, aydınlık karanlık kutusu testi

\begin{abstract}
Thelightdarkbox test is an unconditionalanxiety test used in behavioralphysiology. In this review, some points in the light dark box test have been examined in terms of biological and non-biological factors in order to standardize.
\end{abstract}

Keywords: anxietytests, Light Dark Box Test

\section{Giriş}

Anksiyetenin altında yatan mekanizmaları anlamak ve yeni tedavi ajanları geliştirebilmek için hayvan anksiyete testleri sıklıkla kullanılmaktadır. Genel olarak şartlı ve şartsız olmak üzere ikiye ayrılan anksiyete testlerinden şartlı olan anksiyete testleri elektrik ve ağrılı uyaran içermesi nedeniyle terk edilmektedir.

Aydınlık karanlık kutusu şartsız doğal bir anksiyete düzeneğidir. 1980 yılında Crawley ve Goodwin tarafından tanımlanmıştır (Crawley ve Goodwin, 1980). Siçanların nokturnal yani gececil olmaları esasına dayanan test düzeneği eşit iki bölmeden oluşur. Bu bölmelerden birisi yüksek 1şıla aydınlatılmış diğeri ise karanlıktır. Karanlık ve aydınlık bölmeler arasında geçiş söz konusudur. Insanların karanlıktan korkmasına denk gelecek şekilde sıçan ve fareler de yüksek işıktan korkarlar. Artan anksiyete ile denekler aydınlık bölmeden karanlık bölmeye kaçarlar.

Deney düzeneğinde bakılan parametreler 1987 yılında modifiye edilmiştir (Belzung ve ark., 1987). Genel olarak anksiyolitik etkisi olan ajanlar aydınlık bölmede geçen süreyi ve bölmeler arası geçiş sayısını arttırmaktadır (Imaizumi ve ark., 1994a,b). 
Aydınlık Karanlık Kutusu Testi'nde bakılan davranışlar ve parametreler: Iki ayağı üzerine kalkma davranışı (rearing), iki ayağı üzerine kalkma davranışı ilk gerçekleşinceye kadar geçen süre (rearing latency), dışkılama ve ürinasyon varlığı, aydınlık bölmede geçen süre, karanlık bölmede geçen süre, bölmeler arası geçiş sayısı sayılabilir. Anksiyolitik ajanlar ve tedavi programları rodentlerde aydınlık bölmede geçen süreyi, aydınlık bölme ile karanlık bölmede geçiş sayısını arttırmaktadır.

$\mathrm{Bu}$ derlemede aydınlık karanlık kutusu testine etki eden parametreler biyolojik ve biyolojik olmayan faktörler açısından incelenmiştir.

\section{Aydınlık Karanlık Kutusu Testi’nin Biyolojik Faktörler Açısından Incelenmesi}

\section{Tür}

Aydınlık karanlık kutusu testi ile yapılan çalışmalar incelendiğinde farklı hayvan türlerinin kullandıldığ 1 görülmektedir. Fare (C57BL/6N Fare, Swiss Albino Fare, CD1 Fare), sıçan (Sprague Dawley Sıçan, Wistar Albino Sıçan), zebra balı̆̆ı, tavuk, degu, Vole Prairie, marmoset maymunu ile yapılan çalışmalar mevcuttur (Soulimani ve ark., 1997 ; Hebb ve ark., 2003 ; Singh ve ark., 2013 ;

Sun ve ark., 2014 ; Wang ve ark., 2014 ; Ashkenazy-Frolinger ve ark., 2015 ; Femenía ve ark., 2015 ;

Kesby ve ark., 2015 ; Marco ve ark., 2015 ; Pelloux ve ark., 2015 ; Van Der Pol ve ark., 2015).

Pubmed'de yer alan 307 makale incelendiğinde araştırmalarda \%65,14 fare, \%30,94 sıçan, \%2,28 zebra balı̆̆ $1, \% 0,32$ tavuk, \%0,32 Degu, \%0,32 Vole prairie, \%0,32 fare-siçan ve $\% 0,32$ marmoset maymunu kullanıldığg görülmektedir (Çalışkan ve ark.,2017a).

$\mathrm{Bu}$ veriler 1şığında daha çok fare olmak üzere sıklıkla fare veya sıçanların kullanıldığ bir deney düzeneği olduğu anlaşılmaktadır. Son yıllarda toksikoloji deneylerinden sonra nörofizyolojik çalışmalara da zebra balığının girdiği görülmektedir (Singh ve ark., 2013).

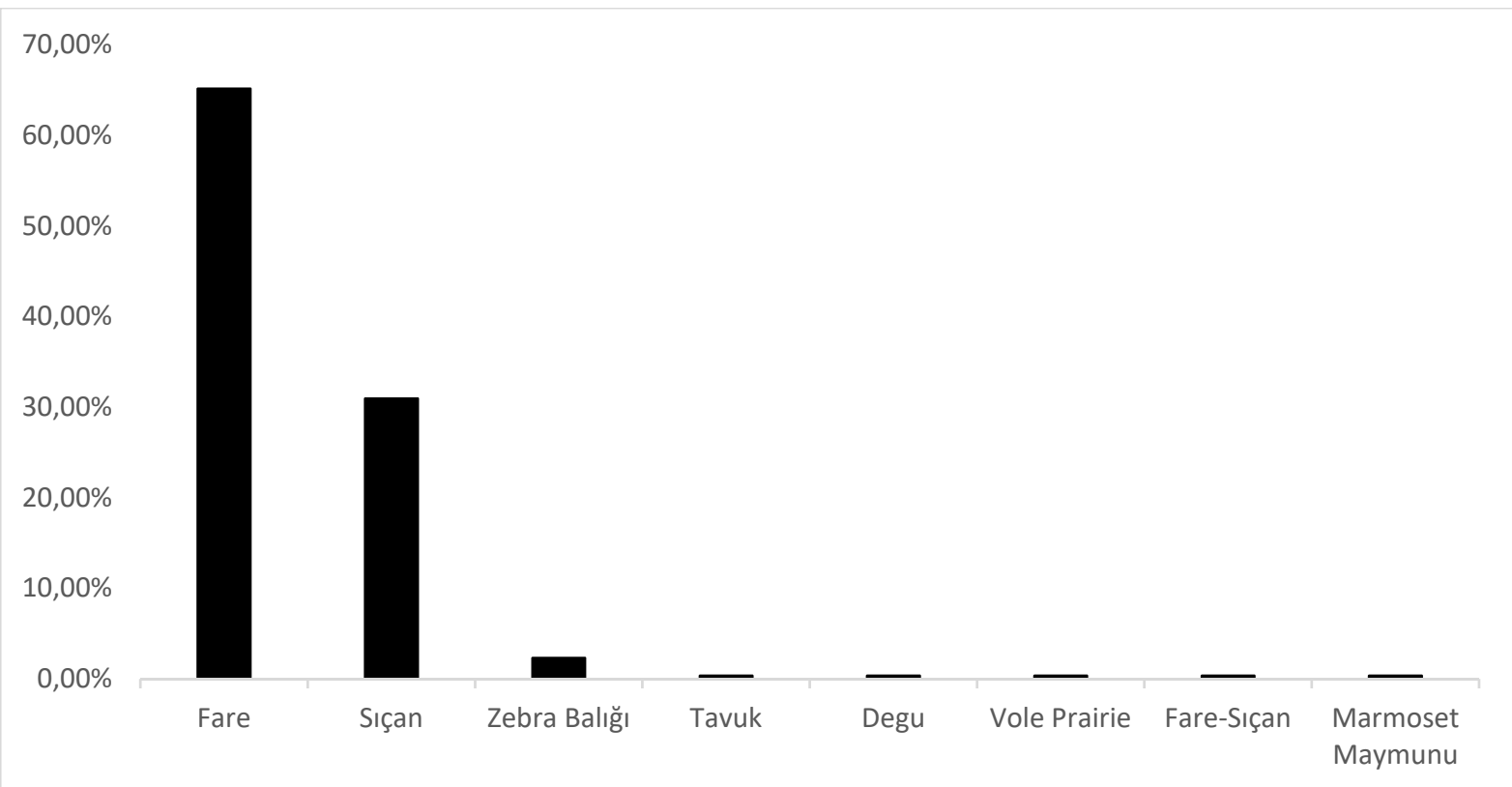

Şekil 1. Aydınlık Karanlık KutusuTesti’nde Tür Seçimi (Çalışkan ve ark.,2017a) 
Tablo 1. Aydınlık Karanlık Kutusu Testi’nde Tür Seçimi

\begin{tabular}{|c|c|}
\hline Tür & Araştırmacılar \\
\hline C57BL/6NFare & Kesby ve ark., 2015 \\
\hline Swiss Albino Fare & Soulimani ve ark., 1997 \\
\hline CD1 Fare & Hebb ve ark., 2003 \\
\hline SpragueDowleySıçan & Femenía ve ark., 2015 \\
\hline Wistar Siçan & Pelloux ve ark., 2015 \\
\hline Zebra Balığı & Singh ve ark., 2013 \\
\hline Tavuk & Van Der Pol ve ark., 2015 \\
\hline Degu & Ashkenazy-Frolinger ve ark., 2015 \\
\hline Vole Prairie & Sun ve ark., 2014 \\
\hline Fare-Siçan & Marco ve ark., 2015 \\
\hline Marmoset Maymunu & Wang ve ark., 2014 \\
\hline
\end{tabular}

\section{Cinsiyet}

Araştırmalarda cinsiyet seçimi incelendiğinde \%66,12 erkek, \%19,54 dişi-erkek, \%7,81 cinsiyeti belirsiz, \%6,51 dişi hayvan kullanılmıştır. Aydınlık karanlık kutusu testinde erkek deneklerin dişi deneklerden daha çok kullanıldığı görülmektedir. Bunun sebebi olarak da dişilerdeki hormonal dalgalanmaların bazal anksiyete seviyelerini etkileyebilmeleri gösterilmektedir. Erkek hayvanların daha çok kullanılması Açık Alan Testi, Yükseltilmiş Artı Labirent Testi, Misket Gömme Testi gibi diğer anksiyete testleri ile ortaktır (Çalışkan ve ark., 2017a). Bazı araştırmacılar çalışmalarında ilginç olarak cinsiyet belirtmemiştir.

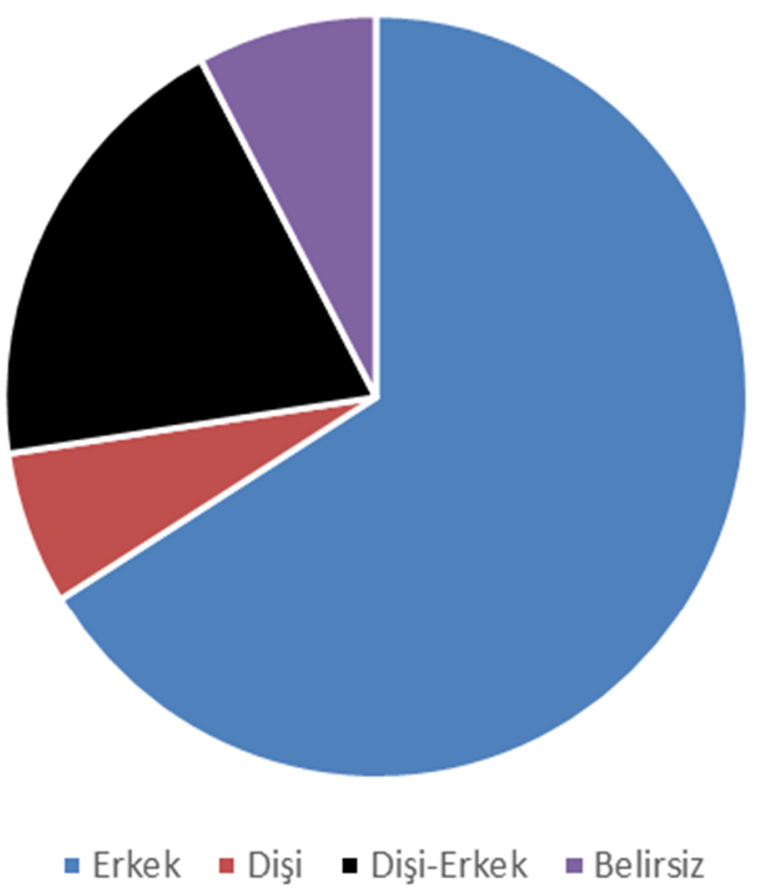

Şekil 2. Aydınlık Karanlık Kutusu Testi’nde Cinsiyet Seçimi (Çalışkan ve ark.,2017a) 


\section{Yaş ve Her Gruptaki Denek Sayısı}

Araştırmanın özelliğine bağlı olarak rodentlerin yaşı belirgin olarak farklılık göstermektedir. Deneklerin yaş aralığ 4-48 haftalık arasında değişmektedir (Gammie ve ark., 2008 ; Mikulecká ve Mares, 2009 ; Adamczyk ve ark., 2012 ; Zlomuzica ve ark., 2012 ; Van'tVeer ve ark., 2013 ; Van Der Pol ve ark., 2015). Bir araştırmada 4 günlük tavuk kullanıldığı görülmektedir (Van Der Pol ve ark., 2015). Pubmed verileri incelendiğinde araştırmacıların belirli bir yaş üzerinde çalışmadığı anlaşılmaktadır.

Çalışmalarda her bir grupta kullanılan denek sayısı 5-60 arasında değişmektedir (Hebb ve ark., 2003 ; Ramos ve ark., 2008 ; Popova ve ark., 2010 ; Izidio ve ark., 2011 ; Wang ve ark., 2014 ; Savignac ve ark., 2016 ; Sharko ve ark., 2016).

Tablo 2. Çalışmalarda Kullanılan Hayvanların Yaş Aralı̆

\begin{tabular}{|c|c|}
\hline Yaş & Araştırmacilar \\
\hline 4 günlük & Van Der Pol ve ark., 2015 \\
\hline 4 haftalık & Mikulecká ve Mares, 2009 \\
\hline 7-12 haftalık & Van'tVeer ve ark., 2013 \\
\hline 16 haftalık & Gammie ve ark., 2008 \\
\hline 16-36 haftalık & Adamczyk ve ark., 2012 \\
\hline 48 haftalık & Zlomuzica ve ark., 2012 \\
\hline
\end{tabular}

Tablo 3. Çalışmalarda Her Gruptaki Denek Saylsı

\begin{tabular}{|c|c|}
\hline Her Gruptaki Hayvan Sayısı & Araştırmacilar \\
\hline 5 & Hebb ve ark., 2003 \\
\hline 10 & Popova ve ark., 2010 \\
\hline 12 & Wang ve ark., 2014 \\
\hline $14-16$ & Sharko ve ark., 2016 \\
\hline $27-28$ & Savignac ve ark., 2016 \\
\hline 43 & Izidio ve ark., 2011 \\
\hline 60 & Ramos ve ark., 2008 \\
\hline
\end{tabular}

\section{Aydınık Karanlık Kutusu Testi’nin Biyolojik Olmayan Faktörler Açısından Incelenmesi}

\section{Test Süresi}

Pubmed'de yer alan 226 makale incelendiğinde araştırmalarda test süresi olarak \%69,46 5 dakika, $\% 22,5610$ dakika, \%3,98 15 dakika, \%1,76 6 dakika, \%0,88 3 dakika, \%0,88 20 dakika ve \%0,44 30 dakika belirlendiği görülmektedir. Aydınlık karanlık kutusu testi'nin sıklıkla 5 dakika uygulandığı anlaşılmaktadır. Bununla birlikte deney süresi 3-30 dakika arasında değişmektedir (Grisel ve ark., 2008 ; Zhang ve ark., 2010 ; Fuster-Matanzo ve ark., 2011 ; Takashima ve ark., 2011 ; Deacon ve ark., 2012 ; Kirshenbaum ve ark., 2014 ; Zhang ve ark., 2014). Yükseltilmiş Artı Labirent Testi, Açık Alan Testi, Delikli Tahta Testi gibi diğer anksiyete testleri aydınlık karanlık kutusu testi ile kombine edilmektedir (Gupta ve ark., 2014; Colla ve ark., 2015). Farklı anksiyete ve depresyon testleri deneklerde yorgunluk ile sonuçlanabilir. Bu yüzden farklı test süreleri uygulanabilir ve test süreleri düşürülebilir. Deney protokolünde gündüz açık alan testi, yükseltilmiş artı labirent, zorunlu yüzme testi gibi davranış deneyleri uygulandığında gece periyodunda (20:00-24:00) aydınlık karanlık kutusu testi uygulanabilir. 


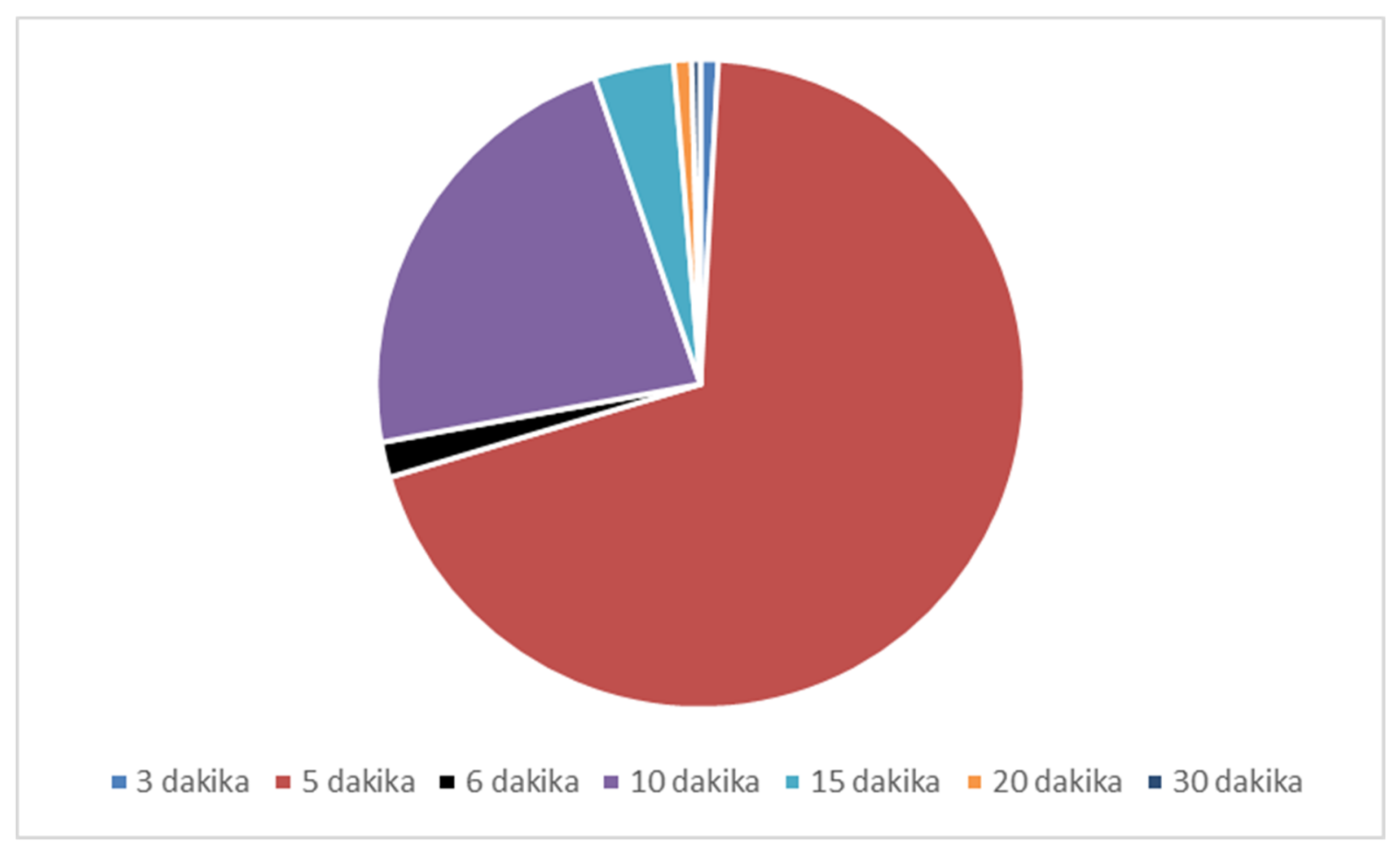

Şekil 3. Aydınlık Karanlık Kutusu Testi'nin Uygulandiğı Süreler (Çallşkan ve ark., 2017b)

Tablo 4.Aydınlık Karanlık Kutusu Testi'nin Uygulandiğ Süreler

\begin{tabular}{|c|c|}
\hline Test Süresi & Araştırmacilar \\
\hline 3 dakika & Deacon ve ark., 2012 \\
\hline 5 dakika & Zhang ve ark., 2010 \\
\hline 6 dakika & Kirshenbaum ve ark., 2014 \\
\hline 10 dakika & Takashima ve ark., 2011 \\
\hline 15 dakika & Fuster-Matanzo ve ark., 2011 \\
\hline 20 dakika & Grisel ve ark., 2008 \\
\hline 30 dakika & Zhang ve ark., 2014 \\
\hline
\end{tabular}

\section{Işık Yoğunluğu}

Çalışmalarda kullanılan 1şık yoğunluğu 20-2200 1x arasında değişmektedir (Turri ve ark., 2001; Kita ve ark. , 2004 ; Biala ve Kruk, 2007 ; Lehmann ve ark., 2010 ; Markovics ve ark., 2012 ; MirandaMorales ve ark., 2014 ; Zhang ve ark., 2014 ; Kirshenbaum ve ark., 2014). Aydınlık karanlık kutusu testi'nin uygulama süresi ve deney düzeneğinin boyutuna bağlı olarak kullanılan 1şık yoğunluğu değişebilmektedir; ancak yapılan çalışmalarda 800-850 lx kullanımı sıktır.

Tablo 5. Aydınlık Karanlık KutusuTesti'nde Kullanılan Işsk Yoğunluğu (Çalışkan ve ark., 2017b)

\begin{tabular}{|c|c|}
\hline Işık Yoğunluğu & Araștırmacilar \\
\hline $20 \mathrm{~lx}$ & Turri ve ark., 2001 \\
\hline $40 \mathrm{~lx}$ & Lehmann ve ark., 2010 \\
\hline $200 \mathrm{~lx}$ & Miranda-Morales ve ark., 2014 \\
\hline $400 \mathrm{~lx}$ & Zhang ve ark., 2014 \\
\hline $850 \mathrm{~lx}$ & Biala ve Kruk, 2007 \\
\hline $1000 \mathrm{~lx}$ & Markovics ve ark., 2012 \\
\hline $1400 \mathrm{~lx}$ & Kita ve ark., 2004 \\
\hline $2000 \mathrm{~lx}$ & Kirshenbaum ve ark., 2014 \\
\hline
\end{tabular}




\section{Diğer Biyolojik Olmayan Faktörler}

Aydınlık karanlık kutusu testi 07:00 -24:00 saatleri arasında; \%94,53 gündüz vaktinde ve $\% 5,47$ gece vaktinde uygulanmıştır. Test odası sessiz olmalıdır. Bütün davranışlar video kamera ile kayıt altına alınmalıdır. Adaptasyon, bakım ve ilaç uygulama yöntemi test sonuçlarını etkileyebilmektedir. Cihaz etanol ile temizlenmeli ve tamamen kuruyuncaya kadar beklenmelidir. Çalışmalarda kullanılan temizleme solüsyonları \%10-70 etanol içermektedir. Aydınlık karanlık kutusu testi $23-25{ }^{\circ} \mathrm{C}$ sıcaklık ve \%50-70 nem oranına sahip odalarda uygulanmalıdır. Bunların dışında yapılan çalışmalarda mevsimsel parametreler bildirilmemiştir.

\section{Sonuç}

Pubmed verileri incelendiğinde aydınlık karanlık kutusu testi; açı alan testi ve yükseltilmiş artı labirent testinden sonra en sık tercih edilen anksiyete testidir. Davranış testi olarak zorunlu yüzme testi gibi depresyon testleri ile ve diğer anksiyete testleriyle birlikte deneklerin davranışları incelenmektedir. Aydınlık karanlık kutusu diğer anksiyete testlerinde olduğu gibi erkek denek kullanımı, gündüz periyodunda uygulama açısından benzerdir. Farklı davranış deneylerinin anksiyete benzeri davranışları arttırabilir ve yorgunluğa neden olabilir. Bu gibi durumlarda aydınlık karanlık kutusu testi akşam periyodunda uygulanabilir.

\section{Kabuller}

Yazarlar herhangi bir finansal katkı almadıklarını beyan etmektedirler. Bu derleme yer alan veriler 2017 yılında Istanbul'da gerçekleşen 3. Uluslararası Ilaç ve Eczacılık Kongresi'nde 259 ve 260 numaralı poster olarak Ingilizce dilinde sunulmuştur.

\section{Kaynaklar}

ADAMCZYK A, MEJIAS R, TAKAMIYA K, YOCUM J, KRASNOVA IN, CALDERON J, CADET JL, HUGANIR RL, PLETNIKOV MV, WANG T. 2012. GluA3-deficiency in mice is associated with increased social andaggressive behavior and elevated dopamine in striatum .Behav Brain Res. 1;229(1):265-72.

ASHKENAZY-FROLINGER T, EINAT H, KRONFELD-SCHOR N. 2015. Diurnalrodents as an advantageous model fo raffective disorders: novel data from diurnaldegu (Octodondegus). $J$ NeuralTransm (Vienna).122 Suppl 1:S35-45.

BELZUNG C, MISSLIN R, VOGEL E, DODD RH, CHAPOUTHIER G. 1987. Anxiogenic effects of methyl-beta-carboline-3-carboxylate in a light / dark choice situation. Pharmacol Biochem Behav. 28 (1): 29-33.

BIAŁA G, KRUK M. 2007. Amphetamine-induced anxiety-related behavior in animal models .Pharmacol Rep.59(6):636-44.

COLLA AR, ROSA JM, CUNHA MP, RODRIGUES AL. 2015. Anxiolytic-likeeffects of ursolicacid in mice. Eur J Pharmacol.758:171-6.

CRAWLEY J, GOODWIN FK. 1980. Preliminary report of a simple animal behavior model for the anxiolytic effects of benzodiazepines.PharmacolBiochemBehav.13(2):167-70.

ÇALIŞKAN H, ERGÜN A, ÖZTÜRK MC, GENÇER ŞH, KILINÇ S, KAYA MO, KILIÇDAĞI M, OSMANOV Z. 2017. In Light Dark Box In Terms Of Biological Factors Analysis. $3^{\text {rd }}$ International Convention of Pharmaceuticals and Pharmacie Congress Poster Presentation. Poster-0260: 435p. 
ÇALIŞKAN H, OSMANOV Z, KILINÇ S, ÖZTÜRK MC, KILIÇDAĞI M, KAYA MO, GENÇER

ŞH, ERGÜN A. 2017. In Light Dark Box Test Non Biological Factors Analysis. 3rd International Convention of Pharmaceuticals and Pharmacie Congress Poster Presentation. Poster-0259: 434p.

DEACON RM, DULU TD, PATEL NB. 2012. Nakedmole-rats: behavioural phenotyping and comparison with C57BL/6 mice.Behav Brain Res.16;231(1):193-200.FEMENÍA T, MAGARA S,

DUPONT CM, LINDSKOG M. 2015. Hippocampal-Dependent Antidepressant Action of the H3 Receptor Antagonist Clobenpropit in a Rat Model of Depression.Int $J$

Neuropsychopharmacol.11;18(9).

FUSTER-MATANZO A, LLORENS-MARTÍN M, DE BARREDA EG, ÁVILA J, HERNÁNDEZ F. 2011. Different susceptibility to neurodegeneration of dorsal and ventral hippocampaldentategyrus: a study with transgenic mice over expressing GSK3 $\beta$.PLoSOne. 6(11):e27262.GAMMIE SC,

SEASHOLTZ AF, STEVENSON SA. 2008. Deletion of corticotropin-releasing factor binding protein selectively impairs maternal, but not intermaleaggression .Neuroscience.2;157(3):502-12.

GRISEL JE, BARTELS JL, ALLEN SA, TURGEON VL. 2008. Influence of beta-Endorphin on anxious behavior in mice: interaction with EtOH. Psychopharmacology (Berl).200(1):105-15.

GUPTA D, RADHAKRISHNAN M, KURHE Y. 2014. Anxiolytic-likeeffects of alverinecitrate in experimental Mouse models of anxiety. Eur J Pharmacol. 742: 94-101.

HEBB AL, ZACHARKO RM, DOMINGUEZ H, LAFOREST S, GAUTHIER M, LEVAC C, DROLET G. 2003. Changes in brain cholecystokinin and anxiety-like behavior following exposure of mice to predator odor. Neuroscience. 116(2):539-51.

IMAIZUMI M, MIYAZAKI S, ONODERA K. 1994a. Effects of xanthine derivatives in a light/dark test in mice and contribution of adenosine receptors. Methods Find. Exp. Clin. Pharmacol. 16: 639-644.

IMAIZUMI M, SUZUKI T, MACHIDA H, ONODERA K. 1994b. A fully automated apparatus for a light/dark test measuring anxiolyticoranxiogenic effects of drugs in mice. Jpn. J. Psychopharmacol. 14: 83-89.

IZIDIO GS, OLIVEIRA LC, OLIVEIRA LF, PEREIRA E, WEHRMEISTER TD, RAMOS A. 2011. The influence of sex and estrouscycle on QTL for emotionality and ethanol consumption. Mamm Genome. 22(5-6):329-40.

KESBY JP, KIM JJ, SCADENG M, WOODS G, KADO DM, OLEFSKY JM, JESTE DV, ACHIM CL, SEMENOVA S. 2015. Spatial Cognition in Adult and Aged Mice Exposed to HighFat Diet. PLoSOne.8;10(10).

KIRSHENBAUM GS, BURGESS CR, DÉRY N, FAHNESTOCK M, PEEVER JH, RODER JC. 2014. Attenuation of mania-like behavior in $\mathrm{Na}(+), \mathrm{K}(+)$ - ATPase $\alpha 3$ mutant mice byprospective therapies fo rbipolar disorder: melatonin andexercise. Neuroscience.28;260:195-204.

KITA A, KOHAYAKAWA H, KINOSHITA T, OCHI Y, NAKAMICHI K, KURUMIYA S, FURUKAWA K, OKA M. 2004. Antianxiety and antidepressant-like effects of AC-5216, a novel mitochondrial benzodiazepine receptor ligand. Br J Pharmacol. 142(7):1059-72. 
LEHMANN ML, BRACHMAN RA, LISTWAK SJ, HERKENHAM M. 2010. NF-kappa B activity affects learning in aversive tasks: possible actions via modulation of the stress axis. Brain BehavImmun. 24(6):1008-17.

MARCO EM, RAPINO C, CAPRIOLI A, BORSINI F, LAVIOLA G, MACCARRONE M. 2015. Potential Therapeutic Value of a Novel FAAH Inhibitor for the Treatment of Anxiety. PLoSOne. $11 ; 10(9)$.

MARKOVICS A, KORMOS V, GASZNER B, LASHGARARA A, SZOKE E, SANDOR K, SZABADFI K, TUKA B, TAJTI J, SZOLCSANYI J, PINTER E, HASHIMOTO H, KUN J, REGLODI D, HELYES Z. 2012. Pituitary adenylatecyclase-activating polypeptide plays a key role in nitroglycerol-induced trigeminovascular activation in mice. NeurobiolDis. 45(1):633-44.

MIKULECKÁ A, MARES P. 2009. Effects of mGluR5 and mGluR1 antagonists on anxiety-like behavior and learning in developing rats. Behav Brain Res. 1;204(1):133-9.

MIRANDA-MORALES RS, NIZHNIKOV ME, WATERS DH, SPEAR NE. 2014. New evidence of ethanol's anxiolytic properties in the infant rat. Alcohol. 48(4):367-74.

PELLOUX Y, COSTENTIN J, DUTERTE-BOUCHER D. 2015. Differential involvement of anxiety and novel type reference levels on oral ethanol consumption in rats. Psychopharmacology (Berl).232(15):2711-21.

POPOVA NK, NAUMENKO VS, CYBKO AS, BAZOVKINA DV. 2010. Receptor-genescrosstalk: effect of chronic 5-HT(1A) agonist 8-hydroxy-2-(di-n-propylamino) tetralin treatment on the expression of key genes in brain serotoninsystemand on behavior. Neuroscience. 11;169(1):22935.

RAMOS A, PEREIRA E, MARTINS GC, WEHRMEISTER TD, IZÍDIO GS. 2008. Integrating the open field, elevated plus maze andl ight/dark box to assessd ifferent types of emotional behaviors in one single trial. Behav Brain Res. 21;193(2):277-88.

SAVIGNAC HM, COUCH Y, STRATFORD M, BANNERMAN DM, TZORTZIS G, ANTHONY DC, BURNET PW. 2016. Prebiotic administration normalizes lipopolysaccharide (LPS)-induced anxiety and cortical 5-HT2A receptor and IL1- $\beta$ levels in malemice. Brain Behav Immun. 52: 120 31.

SHARKO AC, KAIGLER KF, FADEL JR, WILSON MA. 2016. Ethanol-induced anxiolysis and neuronal activation in the amygdala and bed nucleus of the striaterminalis. Alcohol. 50: 19-25.

SINGH A, SUBHASHINI N, SHARMA S, MALLICK BN. 2013. Involvement of the $\alpha 1$ adrenoceptor in sleep-waking and sleep loss-induced anxiety behavior in zebra fish. Neuroscience. 2013. 15;245:136-47.

SOULIMANI R, YOUNOS C, JARMOUNI S, BOUSTA D, MISSLIN R, MORTIER F. 1997. Behavioural effects of Passiflora in carnata L. And itsindole alkaloid and flavonoid derivatives and maltol in the mouse.J Ethnopharmacol.57(1):11-20.

SUN P, SMITH AS, LEI K, LIU Y, WANG Z. 2014. Breaking bonds in maleprairie vole: longtermeffects on emotional and social behavior, physiology, and neurochemistry. Behav Brain Res.15;265:22-31.

TAKASHIMA N, ODAKA YS, SAKOORI K, AKAGI T, HASHIKAWA T, MORIMURA N, YAMADA K, ARUGA J. 2011. Impaired cognitive function and altered hippocampal 
synapsemorphology in mice lacking Lrrtm1, a gene associated with schizophrenia. PLoSOne. 6(7):e22716.

TURRI MG, DATTA SR, DEFRIES J, HENDERSON ND, FLINT J. 2001. QTL analysis identifies multiple behavioral dimensions in ethological tests of anxiety in laboratory mice. CurrBiol. 15;11(10):725-34.

VAN DER POL CW, MOLENAAR R, BUITINK CJ, VANROOVERT-REIJRINK IA, MAATJENS CM, VAN DEN BRAND H, KEMP B. 2015. Lighting Schedule and dimming period in early life: consequences for broiler chicken leg bone development . PoultSci.94(12):2980-8.

VAN'TVEER A, BECHTHOLT AJ, ONVANI S, POTTER D, WANG Y, LIU-CHEN LY, SCHÜTZ G, CHARTOFF EH, RUDOLPH U, COHEN BM, CARLEZON WA JR. 2013. Ablation of kappa-opioid receptors from brain dopamine neurons has anxiolyticlikeeffectsandenhancescocaine-inducedplasticity. Neuropsychopharmacology.38(8):1585-97.

WANG Y, FANG Q, GONG N. 2014. A modified light-dark box test for the common marmoset. NeurosciBull.30(3):394-400.

ZHANG H, SAKHARKAR AJ, SHI G, UGALE R, PRAKASH A, PANDEY SC. 2010. Neuropeptide $Y$ signaling in the central nucleus of amygdala regulates alcohol-drinking and anxiety-like behaviors of alcohol-preferring rats. AlcoholClinExpRes. 1;34(3):451-61.

ZHANG X, WANG B, JIN J, AN S, ZENG Q, DUAN Y, YANG L, MA J, CAO X. 2014. Early deprivation reduced anxiety and enhanced memory in adult male rats. Brain ResBull. 108:44-50.

ZLOMUZICA A, VIGGIANO D, DEGEN J, BINDER S, RUOCCO LA, SADILE AG, WILLECKE K, HUSTON JP, DERE E. 2012. Behavioral alterations and changes in $\mathrm{Ca} /$ calmodulinkinase II levels in the striatum of connexin36 deficientmice .Behav Brain Res.1;226(1):293-300. 
